\title{
REMUNERAÇÃO EM OPÇÕES DE AÇÕES: O SFAS 123 REVISADO*
}

\author{
SHARE OPTION AWARDS: SFAS 123 REVISED
}

\author{
FERNANDO CAIO GALDI \\ Doutorando em Controladoria e Contabilidade da \\ Faculdade de Economia, Administração e Contabilidade \\ da Universidade de São Paulo - Campus Capital \\ Bolsista da FAPESP \\ E-mail: fecaio@fipecafi.org \\ L NELSON CARVALHO \\ Professor Doutor do Departamento de Contabilidade e Atuária \\ da Faculdade de Economia, Administração e Contabilidade da \\ Universidade de São Paulo - Campus Capital \\ E-mail: Inelson@usp.br
}

\section{RESUMO}

Diferentes mecanismos de remuneração têm sido desenvolvidos com o intuito de estimular os empregados a agir com foco na maximização do valor da firma. Uma das maneiras utilizadas pelas empresas na busca desse objetivo é a remuneração vinculada à entrega de ações ou opções de ações da empresa para os empregados (chamada genericamente de remuneração baseada em ações) em troca de seus serviços. Contudo, a utilização desse instrumento acarreta algumas questões controversas para a Contabilidade. Esse tipo de remuneração deve ser reconhecido como despesa? Opções de compra lançadas pela empresa para a remuneração de seus funcionários representam um passivo ou um item do patrimônio líquido? Por qual valor deve ser mensurado esse tipo de remuneração? E qual o período que deve ser considerado para a contabilização? No intuito de regulamentar o assunto, o FAȘB emitiu o SFAS 123 revisado. Este trabalho aborda os temas relacionados com a remuneração baseada em ações, concentrando-se na remuneração com opções de ações, e objetiva expor e analisar o arcabouço conceitual do SFAS 123 revisado. Para isso apresenta a evolução histórica da controversa normatização do tema, discorre sobre os principais conceitos emanados do SFAS 123 revisado e aborda a argumentação utilizada pelo FASB para o embasamento teórico da norma.

Palavras-chave: Remuneração em Opções; SFAS 123; Teoria da Contabilidade; Fair Value.

\section{ABSTRACT}

Different kinds of awards have been developed to stimulate employers to focus on the maximization of the firm value. To reach this target, entities use share-based payment in exchange for the employee services they receive. However, the utilization of these instruments results in controversial questions for Accounting. Should equity awards be recognized as expenses? Is a share option award (issued to pay for employee services) a liability or an equity instrument? What method should be used to measure the value of this instrument? What period of time should be considered to account for this kind of transaction? In order to establish accounting standards for transactions in which an entity exchanges its equity instruments for services, the FASB recently released SFAS 123 revised. This paper discusses share-based payment issues, concentrating on employee share options, and aims to review and analyze the conceptual framework of SFAS 123 revised. It presents the historical evolution of controversial regulations about this theme, discusses the main concepts issued by SFAS 123 revised and addresses FASB's argumentation about the theoretical background of this standard.

Keywords: Employee share options; SFAS 123; Accounting theory; Fair value. 


\section{INTRODUÇÃO}

A competição e a busca de maior eficiência pelas empresas originou a criação de diferentes mecanismos de remuneração com o intuito de estimular os empregados a agir com foco na maximização do valor da firma. Uma das maneiras que tem sido utilizada pelas empresas na busca desse objetivo é a remuneração vinculada à entrega de ações ou opções de ações da empresa para os empregados (chamada genericamente de remuneração baseada em ações). Esse tipo de recompensa, teoricamente, diminui conflitos de agência, pois o empregado passa a ter a meta de maximizar o valor da firma e, assim, aumentar, também, sua remuneração. Watts e Zimmerman (1 986, p.203) constatam que

para que o plano de bônus/remuneração possa prover um incentivo ao administrador para a maximização do valor de uma empresa, o índice de performance no cálculo do bônus deve ser correlacionado com o efeito das decisões dos gestores no valor da firma.

A remuneração baseada em ações busca justamente essa relação simbiótica entre o empregado e o empregador.

A remuneração de um empregado contém, normalmente, uma parcela fixa que pode ser complementada por uma parcela variável. Várias combinações de tipos de remuneração podem ser feitas, mas o fato é que a remuneração baseada em ações tem sido uma ferramenta cada vez mais utilizada pelas empresas. Esse tipo de remuneração tem sido alvo de crescente interesse das empresas nacionais. De acordo com uma pesquisa (Isto é Dinheiro, 2000) feita pela PricewaterhouseCoopers com 76 empresas brasileiras de grande porte (com faturamento médio de US\$500 milhões por ano), 86\% tinham algum plano de remuneração variável. Entre os incentivos de longo prazo, $75 \%$ oferecem fundos de pensão, $48 \%$ têm planos de opção de compra de ações e $10 \%$ têm programas que remuneram com outros valores pagos com base na valorização das ações da empresa. Contudo, a utilização de remuneração baseada em ações acarreta algumas questões controversas para a Contabilidade. Uma opção de compra de uma ação lançada pela empresa para a remuneração de seus funcionários é um passivo ou um item do patrimônio líquido? Esse tipo de remuneração deve ser reconhecido como despesa? E qual o período em que deve ser contabilizada: no momento de sua emissão, quando a opção é exercida, ou outro? Por qual valor? Sua classificação deve ser como item operacional, dado que é componente da remuneração dos funcionários, ou seria mais adequado classificá-la como não operacional? Essas são algumas questões relacionadas com a remuneração baseada em ações.

Dentro desse contexto, o Financial Accounting Standards Board (FASB) se posicionou sobre o tema ao emitir uma norma (SFAS 123) para a contabilização de remunerações em opções de ações em 1995. Contudo, devido à complexidade inerente ao tema, essa norma foi criticada em vários aspectos e, ao final de 2004, foi emitida uma nova versão, chamada de revisada. Interessante salientar que existe uma estrutura conceitual que o FASB segue para a emissão de suas normas, os Statement of Financial Accounting Concepts (SFAC). Essa estrutura articula os objetivos e os critérios que guiam as decisões de regulamentação do FASB (BARTH, BEAVER e WAYNE, 200I). Os SFAC, então, podem ser entendidos como a base teórica que permeia a elaboração das normas do FASB e, por conseqüência, do SFAS 123 revisado.

No Brasil, não há norma para o assunto. No início de 2005, a Comissão de Valores Mobiliários (CVM) emitiu o ofício-circular CVM/SNC/SEP/No. I/2005 que aborda brevemente o tema e orienta, mas não obriga, as companhias a reconhecerem, contabilmente, as despesas referentes à concessão de ações como forma de remunerar os empregados. Entretanto, não especifica como. Um ponto importante desse ofício é a requisição da divulgação pelas empresas que utilizam remuneração em opções de ação, dos detalhes de cada plano nas notas explicativas.

Esse trabalho aborda os temas relacionados com a remuneração baseada em ações, concentrando-se na remuneração com opções de ações, e objetiva expor e analisar o arcabouço conceitual do SFAS 123 revisado visando contribuir com a discussão do tema. O item 2 deste estudo aborda, brevemente, a evolução histórica e a acirrada discussão sobre a normatização do tema nos Estados Unidos, país onde o mercado de capitais é pujante e o mecanismo de remuneração com opções de ações tem sido bastante utilizado. $O$ item 3 relata os principais conceitos e o arcabouço teórico do SFAS 123. O item 4 discorre especificamente sobre a remuneração com opções de ações, o conceito de fair value utilizado no cálculo desses instrumentos e traz a discussão sobre a data de mensuração que deve ser utilizada nessas situações. Para ilustrar os conceitos expostos nessa parte, ela termina com um exemplo de aplicação da norma. O item 5 aborda os conceitos utilizados pelo FASB para o embasamento teórico da norma. O item 6 concluí o trabalho.

dade norte-americanos, emitiu em 1995 o pronunciamento original do SFAS 123 (Accounting for Stock-Based Compensation), que estabelecia que o método preferencial de contabilização para remunerações baseadas em ações deveria ser o 
do fair value (valor justo'). Devido ao grande impacto que essa norma causaria nas demonstrações financeiras, houve grande lobby para alterações na norma por partes interessadas nos seus efeitos. Para Aboody, Barth e Kasznik (200I, p.8), "o debate sobre a emissão do SFAS 123 foi um dos mais controversos politicamente na história do FASB". Assim, na época o FASB apenas recomendava que as empresas adotassem o pronunciamento, mas não as obrigava. O FASB (2004) declara que quando da emissão original do SFAS 123 acreditava que as demonstrações financeiras seriam mais relevantes e representativas da situação da empresa se o valor justo das opções de ações dos empregados fosse incluído no lucro líquido da entidade. O SFAS 123 original permitia, entretanto, que as empresas continuassem a utilizar o $A c$ counting Principles Board Opinion (APB) 25 - que foi emitido em 1972 - e que requeria que a mensuração do custo/despesa de uma remuneração em opções fosse feita pelo seu valor intrínseco, que é o valor em que o fair value do ativo subjacente à opção (por exemplo, da ação) excede o preço de exercício da opção. Pelo APB 25 ( 1 972), as despesas com remuneração em opções de ações são calculadas pela diferença entre o preço da ação e o preço de exercício da opção (na data de mensuração), multiplicado pelo número de opções. A data de mensuração é a data em que o preço de exercício e o número de opções são conhecidos. Com isso, para planos de remuneração em opções com termos fixos, a data de mensuração é a mesma que a data de concessão (grant date) e para planos de opções baseados em performance a data de mensuração é a data na qual a performance é atingida. Como na maioria dos planos de opções fixos o preço de exercício é igual ao preço da ação na data de concessão, as despesas com remuneração com opções, pelo APB 25, eram iguais a zero. Adicionalmente, em seguida ao APB 25, Black e Scholes (1973) demonstraram que uma opção tinha um valor $e$ que esse não era, simplesmente, a diferença entre o preço da ação e o preço de exercício.
Com isso, causou-se uma divergência entre a prática utilizada pelas empresas e a norma emitida pelo FASB, pois poucas entidades aplicavam o SFAS 123 enquanto a maioria continuava a utilizar o APB 25 (que segundo o FASB não representa, adequadamente, a realidade da empresa).

Vale salientar que as empresas que utilizavam o APB 25 deveriam demonstrar em notas explicativas os efeitos que ocorreriam em seu lucro caso tivessem feito o cálculo do impacto da remuneração com opções pelo SFAS 123 , reportando, assim, um lucro pro forma. O FASB (2004, p.6) argumenta que

antes de 2002 - e dos escândalos contábeis - virtualmente todas as entidades continuavam a aplicar o APB 25 ao invés de adotar o método de mensuração pelo fair value na contabilização de remunerações baseadas em ações.

Percebendo que tal situação não era a adequada e no intuito de compatibilizar as demonstrações financeiras publicadas nos padrões norte-americanos (US GAAP) com as publicadas nos padrões internacionais ${ }^{2}$ (IFRS), e impulsionado pelos escândalos contábeis ${ }^{3}$ ocorridos, o FASB retomou as discussões sobre o SFAS 123 em março de 2003. Finalmente, em dezembro de 2004, o FASB emitiu o SFAS 123 revisado (SFAS I23r - Share Based Payment), que suprime a aplicabilidade do APB 25 e suas interpretações correlatas. Adicionalmente, algumas alterações foram incluídas na norma. Com isso, o agente regulador norte-americano espera trazer os seguintes benefícios: i) atender à demanda dos usuários; ii) aumentar a comparabilidade entre as demonstrações financeiras; iii) simplificar o US GAAP e iv) convergir com as normas internacionais ${ }^{4}$. O SFAS 123r tornar-se-á efetivo para as companhias abertas negociadas no mercado norte-americano em 2006. Posteriormente deverá ser aplicado para todas as entidades atuantes nos EE.UU.

\section{CONCEITOS EMITIDOS PELO SFAS 123 REVISADO}

Segundo o FASB (2004), uma remuneração baseada em ações é um acordo no qual (a) um ou mais fornecedores de bens ou serviços (incluindo os empregados) recebem recompensas em ações, opções de ações, ou outros instrumentos de renda variável (títulos patrimoniais) ou (b) quando a entidade incorre em um passivo com fornecedores (I) em valores baseados, pelo menos em parte, no preço das ações da entidade ou outros instrumentos de renda variável ou (2) que requer ou possa requerer sua liquidação pela emissão de ações da entidade.

Para o FASB (2004), os serviços prestados pelos fun- cionários em troca do recebimento de uma remuneração baseada em ações dão origem a uma despesa/custo de remuneração que deve ser reconhecida nas demonstrações financeiras. Hendriksen e Van Breda (1 999, p.232) dizem que "despesas constituem o uso ou consumo de bens e serviços no processo de obtenção de receitas". Dentro dessa linha, Aboody, Barth e Kasznik (200 I, p.2) relatam que:

O FASB acredita que o valor de planos de remuneração em opções de ações são despesas e devem ser reconhecidas no resultado do exercício. Ele argumenta que o lançamento de opções de ações transfere a parte

\footnotetext{
I Definido pelo FASB como sendo o montante pelo qual um ativo/passivo pode ser negociado em uma transação entre partes não relacionadas quando nenhuma das duas está atuando sob pressão.

2 A norma internacional sobre remuneração baseada em ações, a IFRS 2, foi emitida em fevereiro de 2004.

3 Casos Enron, Worldcom, entre outros.

4 A convergência entre as normas contábeis americanas e as normas internacionais é um dos objetivos acordados pelo FASB e pelo IASB.
} 
da propriedade da empresa dos atuais acionistas para os empregados, ou seja, planos de remuneração em opções de ações causam uma diluição nos acionistas existentes. Como os empregados fornecem serviços para a empresa, presumivelmente para gerar lucro, o valor da propriedade transferida representa um custo de geração desse lucro.

Apesar de o SFAS 123r tratar de uma ampla gama de instrumentos de remuneração baseados em ações, o presente trabalho aborda, essencialmente, a remuneração na forma de opções de ações, por se tratar de um item bastante relevante da norma. Também é importante ressaltar que a norma se aplica tanto para empresas de capital aberto, quanto para as de capital fechado, sendo que existem algumas pequenas diferenças no tratamento de cada um dos tipos de sociedade, principalmente devido à disponibilidade de informações para cada uma delas. O enfoque deste trabalho está voltado para as empresas de capital aberto.

\subsection{Conceitos Temporais da Remuneração baseada em Ações}

Nesse ponto, torna-se importante a explanação de algumas definições feitas pelo FASB (2004) que serão utilizadas mais adiante no texto.

- Grant Date (data de concessão): a data na qual o empregado e o empregador chegam a um acordo mútuo sobre os pontos-chave e sobre as condições da remuneração baseada em ações. O empregador torna-se obrigado a emitir títulos patrimoniais (ações, opções etc.) ou a transferir ativos para o empregado do qual requisita os serviços. É a data na qual o empregado começa a se beneficiar, ou a ser adversamente afetado, pelas alterações subseqüentes no preço da ação da entidade empregadora.

- Requisite Service Period (período do serviço requisitado): o período em que o empregado necessita fornecer seus serviços para que seja remunerado com pagamento baseado em ações. O serviço que o empregado é contratado a entregar durante esse período é chamado de requisite service (serviço requisitado).

- Service Inception Date (data de início do serviço): a data em que o requisite service period começa. Normalmente, essa data é a mesma da Grant Date, mas elas podem diferir.

- Vesting Date (data de aquisição de direitos): data na qual o direito do empregado de receber ou reter as ações, opções, outros instrumentos, ou caixa não está mais vinculado à sua prestação de serviços e nem ao atingimento de determinada performance. Data a partir da qual o empregado tem o direito de receber sua remuneração sem ter que fornecer nenhuma contrapartida à entidade.

\subsection{Conceitos-chave da Norma}

Para a adequada determinação dos custos/despesas com a remuneração baseada em ações, dois aspectos fundamentais devem ser resolvidos. O primeiro refere-se aos atributos utilizados para a mensuração da remuneração baseada em ações e, então, à mensuração dos custos/despesas com remuneração. $O$ segundo diz respeito à data em que o preço da ação e os outros fatores pertinentes são fixados para a mensuração do fair value da remuneração baseada em ações (a chamada data de mensuração).

O SFAS 123 revisado requer que os custos/despesas resultantes de todas as transações de pagamentos baseados em ações sejam reconhecidos nas demonstrações financeiras. A medida objetiva para a mensuração desse tipo de transação deve ser o fair value e todas as entidades que utilizem remuneração baseada em ações para seus empregados devem adotar esse conceito na sua contabilização, com exceção de quando usam instrumentos patrimoniais em planos de participação dos empregados ${ }^{5}$ classificados como não compensatórios.

A contabilização de pagamentos em ações para empregados tem como objetivo a evidenciação nas demonstrações financeiras dos serviços prestados por funcionários em troca de títulos patrimoniais (ações, opções etc.) emitidos ou de passivos incorridos e dos respectivos custos/ despesas para a entidade que consumiu esses serviços. $A$ porção do fair value de um título atribuído ao serviço do empregado deve ser líquida de outros valores que o empregado pague (ou se torne obrigado a pagar) para o recebimento desses títulos. Por exemplo, caso o empregado pague $\$ 10$ na data de concessão por uma opção e o fair value da opção é de $\$ 100$, o valor atribuído ao serviço do empregado deve ser de $\$ 90$.

Em suma, o custo/despesa dos serviços recebidos pela empresa e que foram prestados pelo empregado em troca de uma recompensa por títulos patrimoniais da entidade (ações, opções etc.) serão mensurados com base no fair

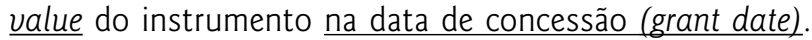
Esse custo/despesa será reconhecido durante o período no qual o empregado deve prestar o serviço em troca de sua remuneração (usualmente o vesting period). Nenhum custo/despesa será reconhecido quando os empregados não entregarem o serviço requisitado.

Para empresas em que as compensações baseadas em ações se enquadrem como passivos ${ }^{6}$, os custos/despesas dos serviços recebidos serão baseados no fair value inicial da gratificação, que será mensurado novamente a cada data de publicação da demonstração financeira até sua liquidação. A mudança no fair value durante o período do serviço requisitado será reconhecida dentro desse período.

Os efeitos fiscais oriundos da aplicabilidade da norma são complexos. Nesse ponto, vale lembrar que esses efei-

\footnotetext{
5 Plano de participação de empregados é definido como um programa que incentiva os empregados a investir nas ações da entidade empregadora. Um exemplo é um plano de bônus em ações, ou a combinação de bônus em ações e aquisição em dinheiro de planos de pensão, estabelecidos para investir, primordialmente, nas ações da entidade empregadora. O AICPA Statement of Positions 93-6 especifica o tipo de tratamento contábil para essas transações.

6 Os critérios para que isso ocorra serão vistos no item 3.3.
} 
tos são oriundos da legislação tributária norte-americana e não devem ser estendidos ao Brasil. De acordo com o SFAS 123r, deve-se reconhecer o imposto de renda diferido resultante das diferenças temporárias entre o resultado contábil e o resultado fiscal. Com relação aos efeitos fiscais diferenciados, a utilização de remuneração baseada em ações pode gerar benefícios em excesso ${ }^{7}$, que devem ser reconhecidos como adições ao capital social. O caixa retido como resultado desses benefícios fiscais deve ser apresentado, na demonstração do fluxo de caixa, como "Caixa gerado pelas atividades de financiamento". A baixa de ativos fiscais diferidos relacionados com benefícios fiscais não realizados associados com os custos/despesas de compensação será reconhecida como despesa de imposto de renda, a menos que haja excesso de benefícios fiscais de remunerações anteriores contabilizadas no capital social.

Adicionalmente, as empresas que utilizarem planos de remuneração baseados em ações devem apresentar as seguintes evidenciações em notas explicativas:

I. a natureza e os termos dos planos de remuneração baseados em ações que existiram durante o período e o potencial efeito desses planos na posição dos acionistas;

2. o efeito dos custos/despesas de compensação vinculados aos planos de remuneração baseados em ações na demonstração do resultado;

3. o método de estimação do fair value dos bens ou serviços recebidos, ou o fair value dos títulos patrimoniais concedidos (ou oferecidos para concessão) no período e
4. os efeitos no fluxo de caixa resultantes dos planos de remuneração baseados em ações.

\subsection{Classificação da Remuneração baseada em Ações}

Uma pergunta recorrente com relação à remuneração baseada em ações é se ela deve ser classificada como passivo ou como patrimônio líquido. A resposta correta é: depende. O SFAS 123r remete-se ao Concepts Statement 6 do FASB (SFAC 6) em que é feita a distinção entre passivo e patrimônio líquido com base na discussão de o instrumento obrigar, ou não, o emissor (dos títulos patrimoniais) a transferir seus ativos (ou a utilizar seus ativos para prover serviços) para o titular desses títulos. Um passivo representa essa obrigação, enquanto um item de patrimônio líquido não. Um exemplo fornecido pelo FASB (2004) é que para uma entidade que emite opções de ações sobre suas próprias ações para utilizá-las como remuneração para seus empregados, a classificação correta resultante da transação é no patrimônio líquido, pois sua liquidação exige somente a emissão de ações, que não é um item do ativo da entidade emissora. Por outro lado, uma obrigação de uma entidade vinculada à valorização de ações (share appreciation right-SAR) com forma de liquidação em dinheiro é um passivo, pois sua liquidação exige a transferência de um ativo para o titular do direito.

Como o presente trabalho aborda, essencialmente, remuneração com opções de ações, a sua classificação deverá ser, normalmente, no patrimônio líquido (capital social).

\section{REMUNERAC̣ÃO COM OPÇÕES DE AC̣ÕES}

Segundo Hull (1996) existem dois tipos básicos de opções: (l) a opção de compra (call) proporciona a seu titular o direito de comprar um ativo em determinada data por determinado preço; (2) a opção de venda (put) dá a seu titular o direito de vender um ativo em certa data por determinado preço.

A data especificada no contrato é conhecida como data de vencimento ou data de exercício. O preço especificado no contrato é conhecido como preço de exercício (strike price). As opções podem ser do estilo americano (exercidas a qualquer momento) ou européias (exercidas em seu vencimento). Para adquirir as opções no mercado, o investidor deve pagar um valor que é chamado de prêmio.

As opções de ações podem ser utilizadas para compensar empregados pelos serviços prestados. Por exemplo, um empregador pode remunerar um empregado com uma opção de ação que lhe dê o direito de comprar 100 ações do empregador pelo preço de $\$ 5$ por ação nos próximos dez anos. Para essas opções, o pagamento do prêmio é feito na forma do serviço do empregado ao invés de em dinheiro. De acordo com o FASB (2004), a maioria das opções de ações utilizadas em remunerações para empregados são opções de compra ${ }^{8}$, mas podem existir opções de venda utilizadas para esse propósito.

Quando utilizada, a remuneração com opção de ações normalmente compõe a parte variável da remuneração de um executivo, constituindo-se em um complemento importante de sua remuneração fixa (salário). A remuneração com opções de ações está vinculada, geralmente, a condições de serviço ou a condições de performance. Ambas são consideradas como condições de aquisição de direitos (vesting conditions) para que a opção possa ser exercida pelo empregado. Para o FASB (2004), a condição de serviço é uma condição que afeta a exercibilidade, o preço de exercício, ou outro fator pertinente utilizado na determinação do fair value da recompensa, que depende do empregado prestar o serviço ao empregador pelo período do serviç̧o requisitado (requisite service period), enquanto a condição

\footnotetext{
7 O benefício fiscal realizado decorrente da diferença do valor da dedução da remuneração em opções pelo empregador para fins de apuração do imposto de renda e o valor das despesas/custos de remuneração em opções reconhecido nas demonstrações financeiras.

8 Por esse motivo, quando esse texto se referir a uma opção, estará se referindo a uma opção de compra, exceto quando expresso o contrário.
} 
de performance é uma condição que afeta a exercibilidade, o preço de exercício, ou outro fator pertinente utilizado na determinação do fair value da recompensa, que se relaciona com os seguintes requisitos: (a) um empregado prestar um serviço por um período de tempo determinado e (b) o atingimento de uma performance especificada que é definida com relação às atividades operacionais do empregador (por exemplo: o crescimento da taxa de retorno sobre os ativos, a realização de uma oferta pública de ações, a obtenção de novas fontes de financiamento, o crescimento nos lucros maior do que a média do mercado, a obtenção de licenças especiais para a exploração de determinado setor etc.).

\subsection{Mensurando o Fair Value das Opções de Ac̣ões}

A norma estabelece os objetivos da mensuração pelo fair value e sua aplicabilidade. Quanto ao objetivo, ela discorre que (FASB, 2004, p.37):

O objetivo da mensuração de instrumentos patrimoniais que foram utilizados como remuneração para funcionários é o de estimar o fair value dos instrumentos que a entidade é obrigada a emitir quando os empregados tiverem prestado o serviço requisitado e satisfeito quaisquer outras condições necessárias para adquirir o direito de se beneficiar desses instrumentos. Essa estimativa é baseada no preço das ações e em outros fatores pertinentes na data de concessão (grant date) e não é mensurada novamente em períodos subseqüentes dentro do método do fair value. (grifos nossos)

Ainda de acordo com o FASB (2004, p.7):

O fair value de uma opção de ação ou instrumento similar deve ser mensurado com base nos preços de mercado observáveis de uma opção com características iguais ou similares à utilizada na remuneração, caso estes sejam disponíveis. Caso contrário o fair value de uma opção de ação ou instrumento similar deve ser estimado com a utilização de técnicas de avaliação como um modelo de precificação de opções[...]

Para Lopes e Martins (2005), nas situações nas quais o mercado existe de forma minimamente organizada, o conceito de fair value confunde-se com o de valor de mercado. Quando esse valor de mercado não está disponível, faz-se necessária a utilização de mecanismos de estimação dos fluxos futuros de caixa para o cálculo do fair value. Assim, - fair value na data de concessão (grant date) das opções de ações (e instrumentos similares) é estimado com a utilização de modelos de precificação de opções ajustados às características do instrumento (com exceção de quando os preços de mercado dos instrumentos financeiros em questão forem observáveis e disponíveis). Adicionalmente, vale salientar que se uma remuneração com opções for modi- ficada depois da data de concessão, as despesas/custos incrementais do serviço do empregado serão reconhecidos no montante em que o fair value da nova remuneração exceder o fair value da remuneração anterior.

O FASB (2004) admite que o fair value seja estimado por modelos que sejam consistentes com o seu objetivo de mensuração, que sejam baseados em princípios estabelecidos da teoria econômico-financeira ${ }^{9}$ e que reflitam todas as características relevantes dos instrumentos ${ }^{10}$, isto é, por um modelo que determine o valor pelo qual os títulos de mesmas características seriam negociados. Os efeitos no preço das opções, decorrentes da existência das condições de aquisição de direito (vesting conditions), são levados em consideração, pois somente são contabilizadas as despesas/ custos com as opções de ações que a entidade espera que vão adquirir o direito de converter as opções em ações (vest) e que realmente adquiram esse direito. Um ponto relevante da norma é que ela estabelece que o fair value na data de concessão não deve refletir as condições de performance e de serviço necessárias para que o empregado tenha o direito de exercer a opção, porque essas são restrições que geram a perda de direito do empregado. Assim, esses fatores não são considerados nos modelos que estimam o fair value, mas são considerados nas premissas da quantidade de empregados que prestam o serviço requisitado e ganham o direito de exercer a opção e, conseqüentemente, no valor das despesas/custos com compensação. Contudo, todas as outras condições de performance e de serviço que afetem o fair value de uma recompensa devem ser consideradas.

Até a data de emissão da norma (dezembro de 2004), os preços de mercado para opções de ações utilizadas na remuneração de empregados geralmente não eram disponíveis. Isso porque mesmo que uma empresa tenha opções negociadas no mercado, as características dessas podem diferir consideravelmente das opções utilizadas na remuneração de empregados. A tabela I $\bullet$ apresenta essas principais diferenças.

Nesse contexto, a aplicação de um modelo de precificação de opções para a contabilização de ações é praticamente indispensável.

Segundo Hull (1996) há seis fatores que afetam os preços das opções: i) o preço atual da ação; ii) o preço de exercício; iii) o tempo para o vencimento; iv) a volatilidade do preço da ação; v) a taxa de juros livre de risco e vi) os dividendos esperados durante a vida da opção.

$\mathrm{Na}$ tabela I, pode-se perceber ao menos duas características importantes que influenciam no valor de uma opção utilizada na remuneração e que devem ser considerados nos modelos de precificação a serem utilizados para a estimação do fair value. São elas a impossibilidade, na maioria dos casos, de o empregado transferir ou hedgear sua posição, o que aumenta a probabilidade que a opção seja exercida antes de seu vencimento contratual para que

\footnotetext{
9 Princípios estabelecidos da teoria econômico-financeira representam proposições fundamentais que formam a base da moderna administração financeira (como o valor do dinheiro no tempo e a risk-neutral valuation).

10 Com exceção das explicitamente excluídas pelo SFAS I23, como as condições de aquisição de direito (vesting coditions) e características de recarga (reload features).
} 
Tabela 1 || Comparação das Opções negociadas em Bolsa com Opções utilizadas na remuneração

\begin{tabular}{|c|c|c|}
\hline Características & Opções negociadas em Bolsa & Opções utilizadas na remuneração \\
\hline $\begin{array}{l}\text { Forma de pagamento: do prêmio pago } \\
\text { pela opção. }\end{array}$ & Em dinheiro & Em serviços do empregado. \\
\hline $\begin{array}{l}\text { Transferência: a possibilidade de vender a } \\
\text { opção para terceiros }\end{array}$ & Transferível & Normalmente, a opção não é transferível. \\
\hline $\begin{array}{l}\text { Exercibilidade ou condições de aquisição } \\
\text { de direito (vesting conditions): condições } \\
\text { contratuais que precisam ser preenchidas } \\
\text { para que se ganhe direito à opção. }\end{array}$ & $\begin{array}{l}\text { Uma opção americana pode ser } \\
\text { imediatamente exercida (não há } \\
\text { condições de aquisição de direito) } \\
\text { porque ela é inteiramente paga } \\
\text { quando adquirida. }\end{array}$ & $\begin{array}{l}\text { Normalmente, a opção não pode ser exerci- } \\
\text { da até que a opção seja paga, ou seja, quan- } \\
\text { do as condições de aquisição de direitos } \\
\text { forem satisfeitas. Por exemplo: o empregado } \\
\text { continua em serviço por um período especi- } \\
\text { ficado de tempo ou satisfaz uma condição } \\
\text { de performance. }\end{array}$ \\
\hline $\begin{array}{l}\text { Duração contratual: o período especifica- } \\
\text { do de tempo no qual a opção se mantém } \\
\text { válida. }\end{array}$ & $\begin{array}{l}\text { Tipicamente uma pequena duração } \\
\text { contratual } \\
\text { (a maior nos EE.UU. é de } 3 \text { anos). }\end{array}$ & $\begin{array}{l}\text { Normalmente, uma longa duração contra- } \\
\text { tual, sendo } 10 \text { anos comum. Geralmente, } \\
\text { reduzida a períodos curtos de tempo, } \\
\text { habitualmente } 90 \text { dias, se o empregado sair } \\
\text { do emprego. }\end{array}$ \\
\hline $\begin{array}{l}\text { Períodos de travamento (blackout } \\
\text { period): período em que o titular da opção } \\
\text { está proibido de exercê-la. }\end{array}$ & $\begin{array}{l}\text { Normalmente, a opção não está } \\
\text { sujeita a períodos de travamento. }\end{array}$ & $\begin{array}{l}\text { Normalmente, a opção está sujeita a perío- } \\
\text { dos de travamento. }\end{array}$ \\
\hline $\begin{array}{l}\text { Possibilidade de Hedge: passível de } \\
\text { hedgear qualquer ganho não realizado da } \\
\text { opção. }\end{array}$ & Existe essa possibilidade. & Normalmente, sujeita a restrições de hedge. \\
\hline
\end{tabular}

Fonte: FASB FAO (2004) adaptado.

seja possível a captura de qualquer ganho não realizado, o que reduz substancialmente o valor de uma opção utilizada na remuneração. Por esse motivo, o SFAS I23r requer, para opções utilizadas na remuneração de empregados e que sejam intransferíveis (e não hedgiáveis), a utilização da menor expectativa de duração da opção ao invés do período de duração contratual.

$\mathrm{O}$ agente regulador norte-americano considera que alguns dos modelos que estão dentro dos requisitos da norma são os modelos chamados de lattice models, que são aqueles que produzem uma estimativa do fair value baseado nas premissas das mudanças de preço de um instrumento financeiro em períodos sucessivos de tempo (por exemplo, o modelo binomial) e os closed form models, que são aqueles que utilizam uma equação para produzir uma estimativa do fair value (por exemplo, o modelo Black-Scholes-Merton). O agente regulador, também, cita a simulação de Monte Carlo como técnica válida para a estimativa do fair value de opções de ações e deixa espaço para outros modelos que estejam adequados à norma. Também fica claro que algumas adaptações precisam ser efetuadas nos modelos para que eles reflitam, adequadamente, as características dos instrumentos utilizados na remuneração de empregados, principalmente porque muitos deles possuem premissas anteriores à sua aplicabilidade e a maioria dos modelos existentes foi desenhada para o cálculo do valor das opções negociadas em Bolsa.

A fórmula de Black-Scholes-Merton, por exemplo, assume que o exercício da opção ocorre no vencimento (opção européia) e que a volatilidade esperada, os dividendos esperados e a taxa de juros livre de risco são constantes durante o período de validade da opção. Normalmente, em uma opção de compra concedida a um empregado, o exercício pode ser efetuado antes do vencimento da opção. Entretanto, apesar dos ajustes que devem ser feitos nos lattice models, nos closed form models e em outros modelos a serem utilizados, eles podem prover estimativas de fair value consistentes com o objetivo da norma. Outro ponto relevante na estimativa do fair value são as premissas utilizadas no modelo para a consideração dos seis fatores que impactam no valor da opção. Essas premissas devem ser razoáveis e sustentáveis (defensáveis) pela entidade.

Assim, o modelo a ser utilizado para o cálculo do fair value de opções de ações utilizadas na remuneração de empregados de uma entidade é flexível" e considera uma certa dose de subjetividade na apuração do valor da opção, pois algumas premissas sobre fundamentos econômicos futuros (por exemplo, a taxa livre de risco) precisam ser estabelecidas. Entretanto, essa foi a metodologia escolhida pelo FASB para a contabilização desses instrumentos.

II O FASB diz acreditar que os lattice models (por exemplo, o modelo binomial) são mais capazes de refletir certas características das opções utilizadas na remuneração de empregados. 
Similarmente ao ocorrido com a emissão do SFAS $133^{12}$, em que Lopes e Lima (200I) corroboram a idéia de que o custo histórico como base de valor perde total sentido na contabilização dos derivativos devendo haver uma revisão da convenção da objetividade, o SFAS 123 revisado nos remete à mesma reflexão.

\subsection{Data da Mensuração da Remuneração em Opções de Ações}

O FASB (2004) concluiu que a remuneração com opções de ações para empregados (e a sua subseqüente emissão caso as condições de aquisição de direitos forem satisfeitas) e os relativos custos/despesas com essa remuneração devem ser mensurados com base no preço da ação e dos outros fatores pertinentes na data em que a remuneração é concedida (grant date).

A data que deve servir como base para o reconhecimento das despesas/custos associados às opções utilizadas na remuneração foi um dos temas mais discutidos na confecção da norma. Como a metodologia do FASB para a aprovação de uma norma contém audiência pública com o recebimento de sugestões e comentários sobre rascunho da norma, além de uma posterior discussão, muitas sugestões foram dadas com relação à data de mensuração. $A$ primeira delas advogava que a data de mensuração deveria ser a data de aquisição dos direitos (vesting date). A justificativa para essa proposta era a de que os empregados só adquiriam o direito de exercer a opção após essa data; até que as duas partes (empregado e empregador) não tivessem preenchido todas as suas obrigações determinadas em contrato, o empregado tinha apenas um direito condicional de receber as opções. A segunda alternativa era tomar como base para mensuração a data de serviço (service date). Diferentemente das alternativas anteriores, a mensuração na data de serviço não se baseia em uma única data para a determinação e reconhecimento das despesas/custos de remuneração. Sua idéia é a de que se deve utilizar o preço da ação nas datas em que o empregado fornece o serviço necessário para ganhar sua recompensa. Sob esse enfoque, um número proporcional de ações sujeitas a uma condição de serviço para a aquisição de direitos, por exemplo, seria mensurada baseada no preço da ação para cada dia em que o empregado prestasse o serviço (na prática poderia ser utilizado o preço médio ponderado das ações no período). Assim, a despesa/custo com remuneração seria mensurada de acordo com o preço da ação durante o período em que o serviço é prestado. Uma terceira alternativa seria a mensuração na data de expiração do serviço, que é a data em que todas as condições relacionadas com o serviço, que podem alterar os termos nos quais o empregado pode exercer sua opção, expiram. Opções utilizadas na remuneração de empregados, normalmente, especificam um período de tempo limitado, quase sempre de 60 a 90 dias após o término do serviço, para que empregados que adquiriram o direito de exercer a opção o façam. A data de expiração para uma opção que tenha 90 dias para ser exercida após o término do serviço é 90 dias anterior à data máxima de vencimento da opção. Caso a opção seja exercida antes, é a data do exercício que deveria ser utilizada na mensuração. $A$ quarta alternativa seria a mensuração na data de exercício. Nesse caso, o preço da ação na data em que o empregado exercesse a opção seria utilizado para a mensuração da despesa/custo de remuneração. Alguns defensores dessa alternativa consideram que opções de ações utilizadas na remuneração são um passivo, ao invés de ser um instrumento do patrimônio líquido, o que é contrário à definição de passivo emanada pelo FASB, pois não há a exigibilidade de transferência de ativos pela entidade. Outros defensores da data de exercício argumentam que o valor intrínseco (que é a diferença entre o preço da ação e o preço de exercício) que o empregado exerce (caso exerça) uma opção é o valor que mensura, apropriadamente, a despesa/custo com remuneração com opções. Outros, ainda, defendem a praticidade e a objetividade dessa medida.

O escopo deste trabalho não permite que se faça uma discussão completa das vantagens e desvantagens de cada método apresentado. Contudo, o método escolhido pelo FASB foi o da data de concessão. O FASB (2004) argumenta que um dos motivos que levou à escolha desse método é que ao decidir quais os termos a serem utilizados na remuneração com opções de ações (e outros instrumentos patrimoniais), tanto o empregado quanto o empregador se basearam no fair value corrente do instrumento a ser negociado (e não seu valor possível em uma data futura). Se as despesas/custos com a remuneração em opções fosse mensurada com base no valor da ação em datas futuras, por exemplo, na data de aquisição dos direitos (vesting date), o valor resultante da remuneração a ser paga ou recebida não seria conhecido na negociação entre as partes. Nessa situação as despesas/custos com remuneração a serem reconhecidas deveriam incluir o valor das condições trocadas pelo serviço e o retorno ao titular da opção das mudanças subseqüentes no seu valor.

Um fator que se poderia questionar com relação à data de concessão ser a data de mensuração ocorre porque opções vinculadas à condições de serviço ou/e de performance não são emitidas até que a entidade tenha recebido do empregado as condições contratadas para esses instrumentos. No entanto, como a entidade se torna contingentemente obrigada, na data de concessão, a emitir os instrumentos contratados caso os empregados satisfaçam as condições necessárias, os empregados recebem um direito de participação no patrimônio da entidade nessa data. O montante que o empregado paga e que o empregador recebe por esse direito de participação é o valor do serviço futuro que o empregado prestará. Como argumenta o FASB (2004), é na data de concessão que esse acordo mútuo acontece, essa é a data que deve ser utilizada como base para a mensuração da 
remuneração com opções de ação. Para clarificar o conceito de "acordo mútuo", o FASB (2004, p. 168) estabelece que "a data de concessão (grant date) é a data na qual o empregado começa a se beneficiar, ou a ser adversamente afetado, pelas alterações subseqüentes no preço das ações da entidade empregadora". Normalmente, pode-se considerar a data em que o acordo/contrato passa a fornecer os termos da remuneração e que o preço de exercício da opção (ou sua formação) do empregado passa a ser conhecido, como a data de concessão. Nesse momento, o empregado fica exposto aos riscos inerentes ao instrumento financeiro ao qual tem o direito caso cumpra as cláusulas contratuais.

\subsection{Exemplo Ilustrativo ${ }^{13}$}

O exemplo, a seguir, tem o intuito de apresentar a forma de contabilização da remuneração com opções de ações de acordo com o SFAS I23r, porém sem esgotar o assunto dado que as variações e combinações possíveis são muitas. Vale lembrar que o cálculo do fair value da opção é de extrema importância e é parte integrante da contabilização desses instrumentos, mas por estar além do escopo do presente trabalho não será aqui detalhado. Nesse contexto, considere a seguinte situação:

A empresa Y, uma sociedade anônima de capital aberto, concede um plano de remuneração em opções de ações no qual se compromete a emitir opções de compra no dinhei$\mathrm{ro}^{14} \mathrm{com}$ prazo de vencimento de 10 anos. Todas as opções de ações passam a ser exercíveis (vesting date) após 3 anos, o que quer dizer que o período de serviço requisitado (requisite service) é de 3 anos. A taxa de imposto de renda é de $35 \%$. As seguintes premissas são traçadas pela empresa na data de concessão $\left(1^{\circ}\right.$. de janeiro de 2005):

Número de opções de ações concedidas

aos empregados: 900.000

Número de empregados que receberam

remuneração em opções de ações:..........................300

Perda de direitos das opções esperada por ano: .........3,0\%

Preço da ação na data de concessão: ......................\$30

Preço de exercício: ...............................................\$30

Prazo de vencimento contratual (PVC)

das opções: 10 anos

Taxa livre de risco durante o PVC , 5 a $4,3 \%$

Volatilidade esperada durante o PVC 40 a $60 \%$

Dividend Yield (Dividendos/Preço da Ação)

esperado durante o PVC. $1 \%$

Fator de exercício subótimo ${ }^{15}$

A partir dessas informações, que devem ser sustentáveis pela empresa, pode ser calculado o fair value da opção na data de concessão. Sabe-se que cada empregado recebeu 3.000 opções (900.000/300). Aplicando-se um lattice model ${ }^{16}$ para a precificação de opções a empresa Y chega ao fair value de \$14,69 por opção. Esse exemplo assume que nenhuma parte da remuneração será capitalizada como parte do custo de um ativo, ou seja, toda a remuneração será considerada como despesa vinculada à prestação do serviço. A perda de direito das opções por ano foi estimada com base na rotatividade histórica da empresa (3\%). Assim, o número esperado de opções de ações que vão adquirir o direito de aquisição (vest) na data de concessão (grant date) é de $821.406\left(900.000 \times 0,97^{\wedge} 3\right)$.

Com isso o total da despesa com remuneração em opções de ações a ser reconhecida durante o período do serviço requisitado em $1^{\circ}$. de janeiro de 2005 é de $\$ 12.066 .454$ $(821.406 \times \$ 14,69)$ e a despesa com remuneração a ser reconhecida em cada ano do período de aquisição dos direitos (vesting period) é de \$4.022.15 I (\$12.066.454/3). Como essa despesa não é dedutível para fins de apuração de imposto de renda, mas poderá ser no futuro ${ }^{17}$ (diferença temporária), cria-se um imposto de renda diferido ativo no valor de $\$ 1.407 .753$ (35\% x \$4.022.1 5 I).

Os lançamentos contábeis seriam os seguintes:

D- Despesas com remuneração em opções

C- Capital Social adicional (remuneração em opções) $\$ 4.022 .151$

D- Imposto de Renda Diferido (ativo)

C- Benefício de Imposto de Renda Diferido (resultado) $\$ 1.404 .753$

Dessa maneira, o impacto líquido do imposto de renda para o ano de 2005 no resultado do exercício da empresa Y seria de $\$ 2.614 .398$ (\$4.022.15I - \$1.404.753). Agora, suponha-se que todas as opções (821.406) fossem exercidas no final de 2012 (prazo máximo do vencimento contratual). A contabilização desse evento seria:
D- Caixa $(821.406 \times \$ 30) \$ 24.642 .180$
D- Capital Social adicional ( $\$ 4.022 .151 \times 3$ anos)
$\$ 12.066 .454$
C- Capital Social: ações subscritas $\$ 36.708 .634$

Se a empresa Y atentasse, por exemplo, no decorrer de 2006 que a sua taxa de rotatividade tivesse alterado de $3 \%$ para $6 \%$, ela deveria realizar os ajustes necessários na contabilização da remuneração em opções de ações. Como o cálculo inicial foi realizado baseado em uma taxa de rotatividade menor (e, portanto, uma taxa de perda de direitos das opções menor), a despesa foi contabilizada

\footnotetext{
13 Adaptado de exemplos do SFAS 123.

14 Tradução do termo "at the money", que significa que o preço de exercício é o mesmo que o preço da ação na data de concessão.

15 O fator de exercício subótimo significa em quantas vezes o preço da ação deve ser maior que o preço de exercício da opção de ação para que a opção seja, normalmente exercida.

16 Os lattice models utilizam o fator de exercício subótimo para calcular a duração esperada da opção (ou seja, a duração esperada é uma saída do modelo). Se uma empresa utiliza o modelo de Black-Scholes-Merton para a precificação da opção, a duração esperada da opção seria utilizada como um dado de entrada do modelo.

17 Essa afirmação é verdadeira com relação à legislação tributária norte-americana. No Brasil, atualmente, não há a possibilidade de dedução desse tipo de despesa para a apuração do imposto de renda.
} 
em um montante maior do que deveria. Assim, o ajuste seria uma reversão dessa diferença no próprio período
(2006) e o estabelecimento do novo valor a ser contabilizado para 2007.

\section{ESTRUTURA CONCEITUAL DO SFAS 123 REVISADO}

Foi apresentada no item 2 deste trabalho, a evolução histórica da normatização da remuneração com opções de ações. Para a evolução do procedimento anteriormente emitido para a contabilização de opções de ações utilizadas na remuneração (o APB 25) até uma norma robusta, porém não obrigatória, com a inclusão dos conceitos modernos de finanças e contabilidade (SFAS I23) foram necessários vinte e três anos. Além disso, passaram-se mais nove anos para que essa norma sofresse algumas alterações e se tornasse obrigatória, que é o caso do SFAS 123 revisado. Nesse ambiente, percebe-se que, no mínimo, essa norma possuí alguma polêmica e relevância. Conforme Hendriksen e Van Breda ( 1 999, p.84), a "contabilidade possui conseqüências econômicas", e a evolução e discussão acerca do SFAS I23r é um bom indicativo dessa afirmação. Reforçando o impacto que as normas contábeis podem exercer na sociedade, Watts e Zimmerman (1986, p.3) relatam:

Os preços das ações e dos bonds não são as únicas variáveis em que as decisões de normas de contabilidade para publicação de demonstrações financeiras afetam o bem-estar de um indivíduo. Um indivíduo na $\mathrm{SEC}^{18}$ está preocupado com o efeito que uma norma contábil pode causar na atitude dos membros do Congresso com relação à SEC, porque isto pode afetar o orçamento da SEC e os recursos que esse indivíduo controla.

Ampliando essa visão, Hendriksen e Van Breda (1999) apontam que, em um ambiente em que as normas contábeis têm conseqüências econômicas, os princípios, postulados e referenciais conceituais possuem valor muito limitado, apesar de não serem completamente inúteis. Aboody, Barth e Kasznik (200 I) classificaram o debate sobre a emissão do SFAS I 23 como um dos mais controversos, politicamente, na história do FASB. Nesse contexto, a análise do arcabouço teórico do SFAS 123r torna-se interessante, pois sua elaboração sofreu impactos políticos relevantes, decorrentes das conseqüências econômicas que essa normatização representa para as entidades que utilizam a remuneração em opções de ações, o que pode ter resultado em conflitos de interesse com relação aos objetivos da norma. Os próximos itens discorrem sobre a argumentação teórica do FASB (2004) - mais de maneira expositiva do que crítica - para a elaboração do SFAS 123 r.

\subsection{Serviço dos Empregados como Ativo}

O SFAS 123r deixa claro que trata os serviços prestados pelos funcionários como ativos para a entidade. Para o FASB (2004), os serviços dos empregados qualificam-se como ativo porque têm as três características essenciais de um ativo. Segundo Wolk, Francis, Tearney (1984, p.264), "muitas definições de ativo podem ser encontradas na literatura contábil. Contudo, a profissão contábil nos Estados Unidos elaborou somente três tentativas formais para a definição de ativo". Os autores referem-se ao Accounting Terminology Bulletin I (1953), ao APB Statement 4 (1970) e ao SFAC 3 (1980). Cada uma dessas definições tem sua qualidade, contudo a evolução conceitual com a publicação de cada uma delas é claramente perceptível. O SFAC 3 definiu ativo como "benefícios econômicos futuros prováveis, obtidos ou controlados por uma entidade, decorrentes de transações ou eventos passados".

Mais recentemente o FASB emitiu o Concepts Statement $N^{\circ} .6$ (SFAC 6) que substitui o SFAC 3, e complementa a definição de ativo (que foi mantida do SFAC 3 em sua essência). Entre as definições emanadas pelo SFAC 6 (1 985), que permeiam o SFAS 123 r, estão as três características essenciais de um ativo, a saber:

(a) ele representa um benefício econômico futuro provável que envolve sua capacidade de, sozinho ou em combinação com outros ativos, contribuir diretamente ou indiretamente com a geração de fluxos de caixa futuros positivos, (b) uma entidade específica pode obter os benefícios e controlar o acesso de outros a eles, e (c) a transação ou outro evento que deu direito à entidade de controlar os benefícios já ocorreu.

A argumentação do FASB (2004) para a classificação dos serviços prestados pelos empregados como ativos está embasada no conceito de ativo, ou seja, os serviços dos empregados têm claramente a capacidade (em combinação com outros ativos como equipamentos, fábricas, ou intangíveis) de contribuir com a geração de fluxo de caixa do empregador pela produção de um produto/serviço; o empregador pode obter o benefício e controlar o acesso de outros a esse benefício e, quando os serviços dos empregados (e suas despesas/custos relacionados) são reconhecidos, o empregador já obteve o benefício. Se os serviços dos empregados (e de outros) não resultassem em benefícios econômicos, nenhuma entidade estaria disposta a pagar uma remuneração (seja em dinheiro ou qualquer outra forma) por sua prestação.

Nesse contexto, os serviços recebidos em troca por remunerações baseadas em ações são ativos, embora somente momentaneamente (porque seu recebimento e uso ocorre simultaneamente). O consumo dos serviços recebidos em troca do lançamento de ações/opções é o evento que gera a despesa/custo. 


\subsection{Serviço dos Empregados como Despesa}

ludícibus (2000, p.l68) define despesa como "a utilização ou o consumo de bens e serviços no processo de produzir receitas". Kam (1986, p.2 I2) relata que:

Na aquisição e no uso dos bens e serviços necessá-

rios para a operacionalização do negócio, uma empresa pode fazer o seguinte:

I. ela pode comprar um bem (uma cesta de serviços), e utilizá-lo no futuro de uma só vez ou em etapas. Um exemplo da utilização em etapas é a compra de uma máquina e o seu uso por cinco anos.

2. ela pode comprar um bem ou serviço e utilizá-lo imediatamente (no período contábil atual). Um exemplo de uso imediato é a aquisição de mão-de-obra. A utilização desses serviços provocam a diminuição no valor de um ativo (normalmente o caixa) ou um aumento no valor de um passivo. (grifos nossos)

A utilização dos serviços prestados pelos empregados gera uma despesa quando os serviços são consumidos imediatamente, ou um custo (que é capitalizado em um ativo), quando seu consumo está ligado diretamente à produção de um ativo que será consumido posteriormente. Assim, independentemente da maneira de pagamento pelos serviços prestados, esse evento deve ser reconhecido como despesa/custo. Quando o pagamento, ou parte dele, é realizado com opções de ações a melhor maneira de se atribuir seu valor é estimar o valor monetário dessas opções.

Durante a elaboração da norma, alguns comentários sobre a emissão de opções utilizadas na remuneração diziam que essa é uma transação direta entre os acionistas atuais e os receptores das opções, então não deveria ser contabilizada. Nesse ponto, pode-se argumentar que pelo postulado da entidade (HENDRIKSEN e VAN BREDA, 1999) deve-se definir qual é a unidade econômica que exerce controle sobre os recursos, aceita a responsabilidade por assumir e cumprir os compromissos e conduz a atividade econômica para se instituir a entidade contábil ${ }^{19}$. Então, os acionistas não se confundem com a entidade, tampouco os serviços prestados pelos seus empregados. Os serviços são prestados para a entidade, e os empregados são contratados por esta. Assim, pelo postulado da entidade as despesas/custos relativas à remuneração de empregados com opções de ações devem ser atribuídas à entidade.

\subsection{Efeitos no Patrimônio Líquido com a Emissão de Opções para Remuneração}

Pelo SFAS 123r a concessão pela empresa do direito de um empregado receber, em troca de seus serviços prestados, opções, resulta em um aumento do capital social da empresa. E, como foi visto, a contrapartida ao aumento do capital social é o reconhecimento de despesas pelo mesmo valor, o que resulta em um impacto nulo no patrimônio líquido ${ }^{20}$

Adicionalmente, caso as opções sejam exercidas e a entidade tenha que emitir ações para honrar sua liquidação, o valor que havia sido contabilizado anteriormente (durante o período em que os serviços requisitados eram prestados) como "Capital Social Adicional", que representam o valor do prêmio da opção recebido pela entidade, serão reclassificados para "Capital Social Subscrito" juntamente com o valor recebido pela emissão das ações.

Entretanto, existem alguns questionamentos adicionais quanto à classificação de remuneração em opções de compra como item do patrimônio líquido. São eles:

- Por que se deve reconhecer as despesas/custos, e o conseqüente aumento do patrimônio líquido, com a remuneração em opções que expirem e não tenham valor?

- Por que se deve reconhecer as despesas/custos, e o conseqüente aumento do patrimônio líquido, com a remuneração em opções que se tornem fortemente fora do dinheiro ${ }^{21}$ antes de o serviço requisitado ter sido prestado?

A argumentação do FASB (2004) para responder a essas duas perguntas tem, basicamente, a mesma fundamentação. O valor da remuneração em opções é mensurado pelo fair value na data de concessão e posteriormente esse não sofre alterações devido a mudanças no valor da ação objeto porque, segundo o FASB (2004), é o empregado - e não o empregador - quem assume os riscos (e os benefícios) das mudanças de preço da ação após a data de concessão. Adicionalmente, assim que o empregado termina a prestação do serviço requisitado e ganha o direito de exercer a opção, o empregador já se beneficiou dos serviços. Houve um impacto no patrimônio líquido, mesmo que não tenha ocorrido a emissão de ações.

\subsection{Método de Mensuração}

Hendriksen e Van Breda (1999) relatam que os métodos mais comumente propostos para a avaliação de opções utilizadas na remuneração de funcionários são:

1. A diferença positiva entre o valor de mercado da ação e o preço de exercício da opção na data de concessão da opção (grant date);

2. A diferença positiva entre o valor de mercado da ação e o preço de exercício da opção na data de aquisição de direito (vesting date);

3. A diferença entre o valor de mercado da ação e o preço de exercício da opção na primeira data em que a opção pode ser exercida;

4. A diferença entre o valor de mercado da ação e o preço de exercício da opção na primeira data em que a opção é exercida:

19 Aquela que será objeto da contabilização dos fatos e eventos que impactem em sua situação econômico-financeira.

20 Apesar de que na norma (SFAS I23r) há a argumentação errônea de que houve aumento do patrimônio líquido (desconsiderando os impactos tributários)

21 Tradução do termo "out of the money" que significa que o preço de exercício é maior que o preço do ativo subjacente. 
5. O custo para a empresa na data do exercício, ajustado pelo efeito em termos de imposto de renda para a empresa;

6. O valor provável da opção para o beneficiário na data de concessão.

Para Hendriksen e Van Breda (1 999, p.493),

o método mais lógico de avaliação é o do valor monetário dos serviços, medido pelo valor da opção na data de concessão (o método 6). Entretanto, a maioria dos contadores evita essa solução, pois é muito subjetiva e depende de especulação a respeito do futuro.

Como foi visto no decorrer do trabalho, essa alternativa é a que está de acordo com os conceitos emitidos pelo SFAS 123r.

Pela discussão e pelos conceitos apresentados anteriormente, percebe-se que as alternativas I a 5 estão relacionadas com o valor intrínseco da opção, diferindo apenas na data base de sua apuração. A alternativa I, inclusive, era a recomendada pelo APB 25 (norma anterior) para opções com termos fixos. Sua utilização resultava em despesas/ custos iguais a zero, pois normalmente eram emitidas opções cujo preço de exercício era igual ao preço de mercado da ação na data de concessão (at the money options).

O conceito de valor intrínseco embora mais objetivo, no sentido de rastreável, do que o fair value, não representa adequadamente o valor de uma opção. O valor de uma opção é composto tanto pelo valor intrínseco quanto pelo seu valor no tempo (time value). O valor intrínseco não considera o valor do direito de se comprar a ação objeto por um preço fixo por um período de tempo especificado (valor no tempo).

Além do valor intrínseco, existe o conceito de valor mínimo. A idéia desse conceito é que um investidor que está interessado em adquirir uma opção de compra estaria disposto a pagar pelo menos um valor que representa o benefício (sacrifício) do direito de diferir o pagamento do preço de exercício até o final do prazo de vencimento da opção. Com isso, o valor mínimo reflete uma parte do valor no tempo de uma opção. Entretanto, o valor mínimo desconsidera o direito dos benefícios decorrentes dos aumentos do preço da ação objeto sem a exposição a perdas adicionais ao valor do prêmio pago pela opção (chamado de valor da volatilidade). Os defensores do valor mínimo alegam que é muito difícil a mensuração do valor da volatilidade, então os modelos de precificação de opções deveriam utilizar a volatilidade como sendo zero, pois, assim, se teria uma medida mais objetiva e facilmente auditável.

Para a adoção do fair value para a mensuração de opções utilizadas na remuneração o FASB (2004) considerou que essa é a medida utilizada pelos participantes do mercado de capitais para a negociação de opções. Além das opções, o fair value também é utilizado para a determinação do valor e negociação de outros instrumentos financeiros. Além da questão pragmática, o FASB atentou para a questão teórica que fundamenta a adoção do fair value ao estabelecer que essa é uma medida superior conceitualmente em relação às suas alternativas (o valor intrínseco e o valor mínimo) na representação do valor de uma opção. Essa foi a posição do grupo de experts (Option Valuation Group ${ }^{22}$ ) que auxiliou o agente regulador na elaboração da norma. Adicionalmente, o FASB (2004) argumenta que esse método aumentará não só a relevância e a confiabilidade, mas também a credibilidade das demonstrações financeiras. Nesse sentido, a utilização do fair value está de acordo com os fundamentos emanados do SFAC I (1978), sobre os objetivos das demonstrações financeiras, que deve ser o de fornecer informações úteis para a tomada de decisões. Como o fair value é superior conceitualmente e pragmaticamente ${ }^{23}$ por propiciar uma medida mais confiável das despesas/custos incorridos pelo empregador para obter os serviços do empregado no mercado, foi o método escolhido pelo FASB.

\section{CONCLUSÕES}

Os objetivos do trabalho são o de apresentar a evolução histórica da normatização de um tema complexo como a remuneração em opções (item 2), de discorrer sobre os principais conceitos emanados do SFAS 123 revisado (item 3 e item 4) e o de demonstrar os conceitos teóricos utilizados (dentro da estrutura conceitual do FASB) para a elaboração da norma (item 5).

Dentro da visão fornecida por Watts e Zimmerman (1986), a teoria contábil pode ser entendida como teoria normativa, ou seja, aquela que diz "como deve ser feito" dentro do conjunto de conhecimento existente, ou teoria positiva, que analisa "como está sendo feito" e objetiva entender quais são os impactos das práticas contábeis e quais as reações dos usuários da Contabilidade. Nesse sentido, a emissão de uma norma contribui com a formação da teoria normativa da Contabilidade, contudo abre ensejos para a aplicação da pesquisa positiva com relação aos seus efeitos nos agentes econômicos usuários da Contabilidade

Aboody, Barth e Kasznik (200 I), a partir de testes empíricos da aplicação da primeira versão do SFAS 123, que obrigava apenas a evidenciação em notas explicativas (mas não o reconhecimento nas demonstrações financeiras) dos efeitos da norma, chegaram à conclusão que os investidores vêem as despesas relacionadas com a remuneração em opções como despesas da empresa. Também descobriram

22 Grupo de especialistas composto por profissionais de consultoria em remuneração, de gerenciamento de risco, de bancos de investimento e da comunidade acadêmica. 23 No sentido de que essa é a medida utilizada para negociação de opções e outros instrumentos no mercado. 
que as despesas com a remuneração em opções são mensuradas de maneira suficientemente confiável para serem associadas aos modelos de avaliação dos investidores.

Nesse contexto, a alteração mais significativa que o SAFS 123 revisado sofreu com relação ao SFAS 123 original, é a do reconhecimento obrigatório do impacto da remuneração com opções de ações nas demonstrações financeiras. De acordo com Aboody, Barth e Kasznik (200I) os investidores, pelo menos os sofisticados, já consideravam essa despesa em seus modelos de avaliação.
Dentro do paradigma da pesquisa positiva, futuros trabalhos podem avaliar como as alterações da norma impactaram nas percepções dos investidores sobre o desempenho das empresas. Adicionalmente, há espaço para testes sobre o tipo de modelo de mensuração utilizado pela empresa para o cálculo do fair value e o respectivo reconhecimento pelo mercado da informação gerada por cada tipo de modelo.

\section{Referências Bibliográficas}

ABOODY, D., BARTH, M. E., KASZNIK, R. SFAS 123 Stock-Based Compensation Expense and Equity Market Values. Working Paper, Social Science Research Network (www.ssrn.com), 2001.

ACCOUNTING PRINCIPLIES BOARD. APB Opinion No. 25 Accounting for stock issued to employees. 1972.

BARTH, M. E.; BEAVER, W.H.; WAYNE, R.L.. The relevance of the value relevance literature for financial accounting standard setting: another view. Journal of Accounting and Economics 31: 77-104, 2001.

BLACK, F; SCHOLES, M.. The Pricing of Options and Corporate Liabilities. The Journal of Political Economy 81 (May/June): 637-654, 1973. COMISSÃO DE VALORES MODILIÁRIOS. Ofício-Circular/CVM/SNC/SEP/No.1/2005. (www.cvm.gov.br)

FINANCIAL ACCOUNTING STANDARDS BOARD. Statement of Financial Accounting Standards No. 123, Share Based Payment. Connecticut: FASB, 2004. Statement of Financial Accounting Standards No. 123, Share Based Payment - Frequently Asked Questions (FAQ). Connecticut:

FASB, 2004

Statement of Financial Accounting Standards Concepts No. 1, Objectives of Financial Reporting by Business Enterprises. Connecticut: FASB, 1978

Statement of Financial Accounting Standards Concepts No. 6, Elements of Financial Statements. Connecticut: FASB, 1985.

HENDRIKSEN, E. S.; VAN BREDA, M. F.. Teoria da Contabilidade. São Paulo: Atlas, 1999.

HULL, J.. Introdução aos mercados futuros e de opções. São Paulo: Cultura, 1996.

ISTO É DINHEIRO. Sócio do patrão: Há cada vez mais formas de ganhar parte do salário em ações. São Paulo: ed. 147, 2000.

IUDÍCIBUS, S.. Teoria da Contabilidade. São Paulo: Atlas, 2000.

KAM, V.. Accounting Theory. New York: Wiley, 1986.

LOPES, A.B.; LIMA, I.S.. Perspectivas para a pesquisa em Contabilidade: o impacto dos derivativos. Revista Contabilidade e Finanças-USP No.26. São Paulo, 2001, p.25-42.

LOPES, A. B.; MARTINS, E.. Teoria da Contabilidade: uma nova abordagem. São Paulo: Atlas, 2005.

WATTS, R. L.; ZIMMERMAN, J. L.. Positive Accounting Theory. New Jersey: Prentice-Hall, 1986.

WOLK, H.I.; FRANCIS, J.R.; TEARNEY, M.G.. Accounting Theory: a conceptual and institutional framework. California: Kent Publishing, 1984.

\section{NOTA - Endereço dos autores}

Universidade de São Paulo

Faculdade de Economia, Administração e Contabilidade

Departamento de Contabilidade e Atuária
Av. Prof. Luciano Gualberto, 908 - Cidade Universitária

São Paulo - SP

05.508-900 